\title{
Comparative Analysis for Surface Roughness of Al Alloy 6061 using MLR and RSM
}

\author{
Kiran A Patel \\ Research Scholar, \\ PAHER University, Udaipur, Rajasthan, India
}

\begin{abstract}
Burnishing is a chip less finishing method which employs a rolling tool pressed against the work piece for achieving plastic deformation of the surface layer. Roller burnishing process is largely considered in industrial cases in order to restructure surface characteristic. The main aim of this study is to compare the prediction accuracy of Response surface methodology (RSM) and Multiple Linear Regressions (MLR) model for Surface roughness. Roller burnishing process is employed on Al alloy work piece for current study. In the present work the effect of burnishing parameter like speed, Interference, feed and the number of passes is going to be examined on the surface quality and its wearing characteristics of Al Alloy 6061.Result and comparative data clearly indicate the better prediction capability of the RSM over the MLR model.
\end{abstract}

\section{Keywords}

Burnishing, Surface Roughness, RSM, MLR, DOE, Al alloy 6061 .

\section{INTRODUCTION}

Machining is a process in which excess stock is removed from a piece of raw material to get desired final shape and size. The work piece is subjected to large amounts of mechanical stress and localized heating due to tool wear, which impart its own mark on the mechanical surface. Also the work piece and tool together with the machine on which they are mounted subjected to vibration. Due to these reasons, the surface of the machined component is going to damage.

Machined surface by conventional process such as turning and milling have inherent irregularities and defects like tool marks and scratches that cause energy dissipation (friction) and surface damage (wear). To overcome these complications, conventional finishing processes such as grinding, honing, and lapping have been traditionally employed. During recent years, more attention has been taken to the post-machining metal finishing operations for the outer layer, for which burnishing process is one of the best methods which improves the surface characteristics by plastic deformation of the surface layer. Besides producing a good surface finish, the burnishing process has additional advantages over the machining processes, such as securing increased hardness, corrosion resistance and fatigue life as a result of producing compressive residual stress[1] [2].

Fig. 1 shows the basic layout of roller burnishing process for plastic deformation of the material which improves the surface texture. Burnishing is a cold working process in which plastic deformation occurs by applying a pressure through a very hard and smooth ball or roller on metallic surfaces. It is a finishing and strengthening process. Improvements in surface finish, surface hardness, wear resistance, fatigue resistance, yield and tensile strength and corrosion resistance can be achieved by the application of this process.

\author{
Pragnesh K Brahmbhatt, Ph.D \\ Associate Professor, Government Engineering \\ College, Modasa, Gujarat, India
}

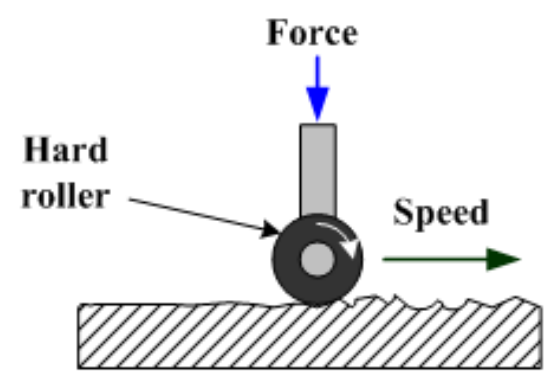

Roller burnishing

Fig 1: Basic layout of roller burnishing process

\section{LITERATURE REVIEW}

El-Axir et al. used simple newly designed internal ball burnishing tool to burnish the internal machined surfaces. They carried out an experiment on AA 2014 with having diameter $100 \mathrm{~mm}$ and analyzed effect ball burnishing parameters using the response surface method (RSM). They found a significant improvement in out-of-roundness and surface micro hardness of work piece has been obtained without the need for the difficult to set-up grinding equipment normally used for inner surfaces super-finishing [3]. El-Axir et al. investigated the effect of ball burnishing parameters burnishing speed, feed rate, depth of penetration and number of passes on surface roughness of AA 2014 using a carbon chromium steel ball. The experiment was designed using RSM with Box and Hunter method. Improve surface average roughness upto $0.14 \mu \mathrm{m}$ [4]. Sagas and Kahraman have studied the effect of the main burnishing parameters burnishing force, feed rate and the number of passes on surface hardness and examined using full factorial design and analysis of variance (ANOVA) to find out the effect of burnishing parameters [5]. Sagbas studied an optimization of ball burnishing on 7178 aluminium alloy with stainless steel ball using a desirability function approach (DFA) and the quadratic regression model was developed to predict surface roughness using RSM with rotatable central composite design (CCD) and considered burnishing force, the number of passes, feed rate and burnishing speed were as model variables[6]. Travieso-Rodríguez et al. analyzed the ball burnishing process is done to improve the surface finish of aluminium A92017 and steel G10380 with concave and convex surfaces and considering the curvature radius as a parameter along with speed and feed with tungsten carbide ball. They concluded that for aluminium Al 92017, better results obtain with a smaller radius in convex surfaces and with a bigger radius in concave surfaces. For steel 1038 the prior peak height as parameters on a milling machine, affect the indexes of surface roughness [7]. Grzesik et al. carried out the functional comparison for improving the surface finish of low alloy $41 \mathrm{Cr} 4$ steel with a hardness of about $57 \mathrm{HRC}$ with CBN hard turning, Si3N4 ceramic ball burnishing and super finishing techniques which shows that Dry hard turning produced initial 
surface profiles with regular tool nose traces and surface roughness with the $\mathrm{Ra}=0.5 \mathrm{~mm}$ which was reduced to about $0.2 \mathrm{~mm}$ by ball burnishing and to about $0.06 \mathrm{~mm}$ by super finishing [8].

The literature reveals that work on the burnishing process has been conducted by many researchers and the process also improves the properties of the component. Some researchers have been carried out recently to improve surface characteristics by using a burnishing process. It seems that the design of the experiment is carried out using some methods such as RSM (Response Surface Methodology), DFA (Desirability Function Approach), FEM (Finite element method), ANOVA (Analysis Of Variance), MLR (Multiple Linear Regressions) and Taguchi method.

The present work, aims at systematically studying the effect of process parameters like Speed, Feed, Interference, the Number of passes and their interactions on the surface finish of the component surface produced by burnishing tool. Experiments will be planned according to statistical design of experiments using RSM for the development of mathematical models. Comparative analysis of the MLR and RSM is done to check the better prediction capability of the model.

\section{MATERIAL}

Aluminum alloy 6061 round bar of $40 \mathrm{~mm} \varnothing$ size has been used as a work piece material for the present experiments with tungsten carbide single roller burnishing tool. Al 6061 is especially hot-worked aluminum having a chemical composition as shown in Table 1. with good hardness and toughness properties. It is used for extreme load conditions such as hot-work forging, extrusion etc. It has varied practical applications such as manufacturing of punching tools, mandrels, mechanical press forging die, plastic mould and die-casting dies, aircraft landing gears, helicopter rotor blades and shafts. The working life and dimensional accuracy of Al 6061 can be improved with suitable heat treatment.

Table 1. Chemical composition of material

\begin{tabular}{|c|c|}
\hline Constituents & \% Composition \\
\hline $\mathrm{Al}$ & 97.5 \\
\hline $\mathrm{Cr}$ & 0.1 \\
\hline $\mathrm{Cu}$ & 0.1 \\
\hline $\mathrm{Fe}$ & 0.5 \\
\hline $\mathrm{Mg}$ & 0.8 \\
\hline $\mathrm{Mn}$ & 0.15 \\
\hline $\mathrm{Si}$ & 0.5 \\
\hline $\mathrm{Ti}$ & 0.15 \\
\hline $\mathrm{Zn}$ & 0.15 \\
\hline
\end{tabular}

\subsection{Experimental design}

The four machining parameters considered for this study are Spindle speed (RPM), feed ( $\mathrm{mm} / \mathrm{rev})$, Interference $(\mathrm{mm})$ and No of tool pass. The parameters are set at five levels each. The summary of the parameters is shown in Table 2 .

Table 2. Process parameters and their levels

\begin{tabular}{|c|c|c|c|c|c|}
\hline \multirow{2}{*}{$\begin{array}{c}\text { Process } \\
\text { parameter }\end{array}$} & \multicolumn{5}{|c|}{ Level } \\
\hline & $(-2)$ & $(-1)$ & (0) & (1) & (2) \\
\hline $\begin{array}{l}\text { Spindle } \\
\text { speed } \\
\text { (X1) }\end{array}$ & 50 & 250 & 450 & 650 & 850 \\
\hline $\begin{array}{c}\text { Interference } \\
\text { (X2) }\end{array}$ & 2 & 3.5 & 5 & 6.5 & 8 \\
\hline
\end{tabular}

\begin{tabular}{|c|c|c|c|c|c|}
\hline Feed (X3) & 0.024 & 0.044 & 0.064 & 0.084 & 0.104 \\
\hline $\begin{array}{c}\text { No. of pass } \\
(\mathrm{X} 4)\end{array}$ & 1 & 2 & 3 & 4 & 5 \\
\hline
\end{tabular}

\section{EXPERIMENTAL WORK}

The experiments were carried out on the HMT lathe machine, model ECONO CNC 26. The work piece dimension is $40 \mathrm{~mm}$ diameter. The cutting conditions were randomized. A Mitutoyo surface roughness tester was used to measure the Ra.

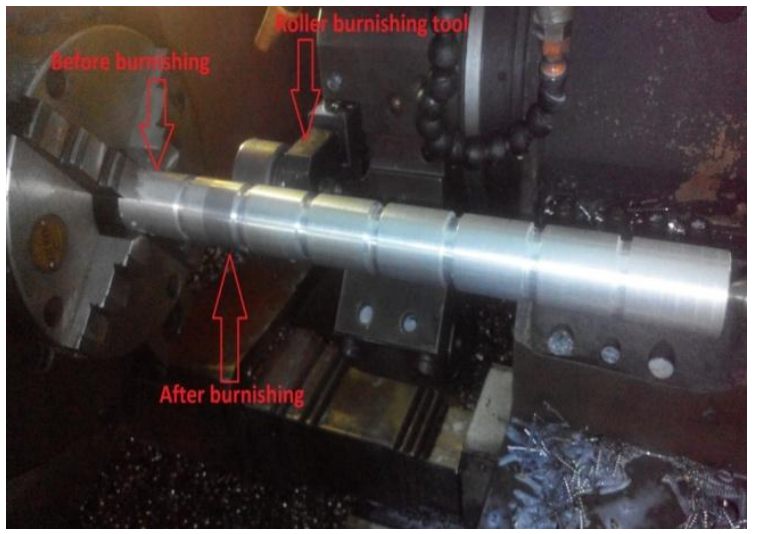

Fig 2: View of experimental setup

The Roller burnishing process experiments were conducted with the process parameter levels set as given in Table 2, to study the effect of process parameters over the output parameters. Experiments were conducted according to the test conditions specified by the second order central composite design for surface roughness. Altogether 31 experiments were conducted using response surface methodology and values of surface roughness were measured using surface roughness tester as given in Table 3 .

Table 3. Coded Values and Real Values of the Variables

\begin{tabular}{|c|c|c|c|c|}
\hline $\begin{array}{c}\text { Sr. } \\
\text { No }\end{array}$ & $\begin{array}{c}\text { X1 } \\
\text { Coded }\end{array}$ & $\begin{array}{c}\mathbf{X 2} \\
\text { Coded }\end{array}$ & $\begin{array}{c}\mathbf{X 3} \\
\text { Coded }\end{array}$ & $\begin{array}{c}\mathbf{X 4} \\
\text { Coded }\end{array}$ \\
\hline 1 & 0 & 0 & 0 & 0 \\
\hline 2 & +2 & -2 & -2 & +2 \\
\hline 3 & -2 & -2 & -2 & -2 \\
\hline 4 & +2 & +2 & +2 & +2 \\
\hline 5 & +2 & +2 & -2 & -2 \\
\hline 6 & -2 & -2 & +2 & -2 \\
\hline 7 & 0 & 0 & 0 & 0 \\
\hline 8 & 0 & 0 & 0 & +2 \\
\hline 9 & -2 & -2 & +2 & -1 \\
\hline 10 & 0 & 0 & 0 & 0 \\
\hline 11 & -2 & +2 & +2 & +2 \\
\hline 12 & -1 & 0 & 0 & 0 \\
\hline 13 & +2 & -2 & +2 & -2 \\
\hline 14 & 0 & 0 & 0 & 0 \\
\hline 15 & 0 & 0 & 0 & 0 \\
\hline 16 & +2 & +2 & +2 & -2 \\
\hline 17 & +2 & -2 & -2 & -2 \\
\hline 18 & +1 & 0 & 0 & 0 \\
\hline 19 & -2 & -2 & -2 & +2 \\
\hline
\end{tabular}




\begin{tabular}{|c|c|c|c|c|}
\hline 20 & +2 & +2 & -2 & +2 \\
\hline 21 & 0 & 0 & 0 & 0 \\
\hline 22 & -2 & +2 & -2 & -2 \\
\hline 23 & 0 & -2 & 0 & +1 \\
\hline 24 & +2 & -2 & +2 & +2 \\
\hline 25 & 0 & 0 & 0 & 0 \\
\hline 26 & 0 & 0 & 0 & 0 \\
\hline 27 & 0 & 0 & 0 & +1 \\
\hline 28 & 0 & +2 & -2 & 0 \\
\hline 29 & -2 & 0 & +2 & -2 \\
\hline 30 & 0 & +2 & +1 & 0 \\
\hline 31 & -2 & +2 & -2 & +2 \\
\hline
\end{tabular}

$\mathrm{X} 1, \mathrm{X} 2, \mathrm{X} 3$, and $\mathrm{X} 4$ represent coded and real values of various factors

\section{RESULTS AND DISCUSSION}

\subsection{Multiple linear regression analysis}

A multiple linear regression model correlates the response with the factors which have a strong effect on the performance of a process. By employing the parameters with their levels for each of the experimental runs in the design matrix the general equation for the proposed second order regression model to predict the response can be written as:

Surface Roughness

$\mathrm{Ra}=0.267019-0.000138468(\mathrm{X} 1)-0.071057(\mathrm{X} 2)+$ 0.0286383 (X3) - 0.0279388 (X4)

Table 4. Estimated Regression Coefficients for Surface Roughness using MLR

\begin{tabular}{|c|c|c|c|c|}
\hline Term & Coef & SE Coef & $\mathbf{T}$ & $\mathbf{P}$ \\
\hline CONSTANT & 0.267019 & 0.033807 & 7.89815 & 0.000 \\
\hline $\mathbf{X 1}$ & -0.000138 & 0.023283 & -0.00595 & 0.995 \\
\hline $\mathbf{X 2}$ & -0.071057 & 0.022413 & -3.17027 & 0.004 \\
\hline $\mathbf{X 3}$ & 0.028638 & 0.022810 & 1.25546 & 0.220 \\
\hline $\mathbf{X 4}$ & -0.027939 & 0.023302 & -1.19898 & 0.241 \\
\hline \multicolumn{5}{|c|}{$\mathrm{R}-\mathrm{Sq}=36.90 \% \quad \mathrm{R}-\mathrm{Sq}(\mathrm{pred})=1.58 \%$} \\
\hline
\end{tabular}

With the help of Multiple linear regression model the value of T-test and respective p-value are represented in Table 4.

To check the significance of the developed models Analysis of variance (ANOVA) is employed. The $\mathrm{P}$ value of 0.01457 (Table 5.), which is less than 0.05 represent the statistical significance model. Normal probability plot for experiment design are shown in fig. 3 which represent the closeness of prediction with a regression line. MLR prediction will be compared with the RSM prediction to check the feasibility.

Table 5. Analysis of Variance for Surface Roughness using MLR

\begin{tabular}{|c|c|c|c|c|c|}
\hline Source & DF & SS & MS & F & P \\
\hline Regression & 4 & 0.5382 & 0.13455 & 3.801 & 0.0145 \\
\hline Residual Error & 26 & 0.9204 & 0.03540 & & \\
\hline Total & 30 & 1.4586 & & & \\
\hline
\end{tabular}

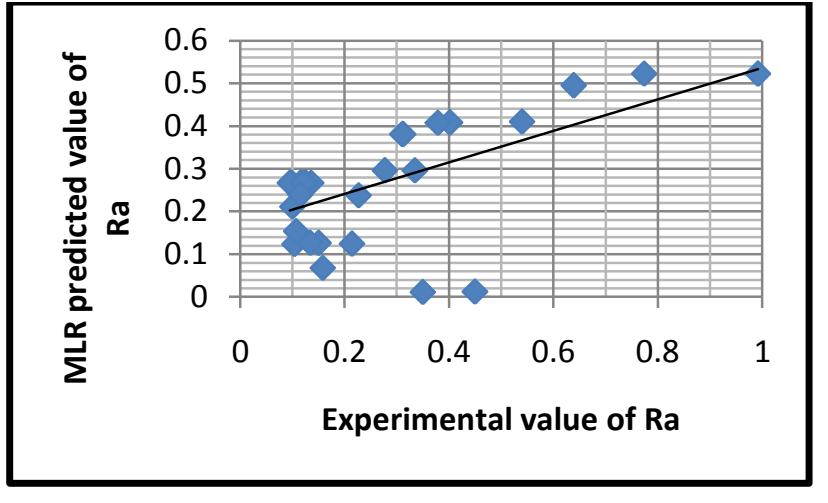

Fig 3: Regression plot for Ra using MLR

5.2 Response surface methodology analysis Empirical model for the Surface roughness ( $\mathrm{Ra})$, in terms of input machining parameters speed, interference, feed and depth of cut were developed by using the RSM using Coef value as shown in Table 6. The pooled version of ANOVA for surface roughness indicates that the $\mathrm{P}$ values for the quadratic terms $\mathrm{X} 3 * \mathrm{X} 3$ and the interaction terms $\mathrm{X} 1 * \mathrm{X} 4$ are above 0.05 which describe its non significant value. In this case $\mathrm{X} 1, \mathrm{X} 2$, $\mathrm{X} 3, \mathrm{X} 4, \mathrm{X} 1 * \mathrm{X} 1, \mathrm{X} 2 * \mathrm{X} 2, \mathrm{X} 4 * \mathrm{X} 4, \mathrm{X} 1 * \mathrm{X} 2, \mathrm{X} 1 * \mathrm{X} 3, \mathrm{X} 2 * \mathrm{X} 3$, $\mathrm{X} 2 * \mathrm{X} 4, \mathrm{X} 3 * \mathrm{X} 4$ are significant model terms. The prediction equation for surface roughness using RSM is as below by eliminating non significant value. The "Pred R-Squared" of 0.9501 is in reasonable agreement with the "Adj R-Squared" of 0.9921 .

Surface Roughness

$\mathrm{Ra}=0.110840+0.006024 * \mathrm{X} 1-0.070690 * \mathrm{X} 2+0.026662 *$ $\mathrm{X} 3-0.019587 * \mathrm{X} 4+0.015689 * \mathrm{X} 12+0.035242 * \mathrm{X} 22+$ $0.010256 * \mathrm{X} 42-0.006538 * \mathrm{X} 1 * \mathrm{X} 2+0.012052 * \mathrm{X} 1 * \mathrm{X} 3$ $0.026860 * \mathrm{X} 2 * \mathrm{X} 3-0.021932 * \mathrm{X} 2 * \mathrm{X} 4-0.019263 * \mathrm{X} 3 * \mathrm{X} 4$ (ii)

Table 6. Estimated Regression Coefficients for Surface Roughness using RSM

\begin{tabular}{|c|c|c|c|c|}
\hline Term & Coef & SE Coef & $\mathbf{T}$ & $\mathbf{P}$ \\
\hline CONSTANT & 0.110840 & 0.006493 & 17.071 & 0.000 \\
\hline $\mathrm{X1}$ & 0.006024 & 0.002859 & 2.107 & 0.049 \\
\hline $\mathrm{X} 2$ & -0.070690 & 0.002943 & -24.020 & 0.000 \\
\hline X3 & 0.026662 & 0.002823 & 9.445 & 0.000 \\
\hline $\mathrm{X4}$ & -0.019587 & 0.003112 & $\begin{array}{l}-6.294 \\
\end{array}$ & 0.000 \\
\hline X1*X1 & 0.015689 & 0.00686 & 2.287 & 0.036 \\
\hline $\mathrm{X} 2 * \mathrm{X} 2$ & 0.035242 & 0.004045 & 8.712 & 0.000 \\
\hline $\mathrm{X3} * \mathrm{X3}$ & 0.002324 & 0.007214 & 0.322 & 0.752 \\
\hline$X 4 * X 4$ & 0.010256 & 0.004597 & 2.231 & 0.040 \\
\hline $\mathrm{X} 1 * \mathrm{X} 2$ & -0.006538 & 0.001567 & -4.173 & 0.001 \\
\hline $\mathrm{X1} 1 \mathrm{X3}$ & 0.012052 & 0.001454 & 8.291 & 0.000 \\
\hline $\mathrm{X1} 1 * \mathrm{X4}$ & -0.002549 & 0.001589 & -1.604 & 0.128 \\
\hline $\mathrm{X} 2 * \mathbf{X} 3$ & -0.026860 & 0.001515 & -17.733 & 0.000 \\
\hline $\mathrm{X} 2 * X 4$ & 0.021932 & 0.001543 & 14.215 & 0.000 \\
\hline $\mathrm{X3} 3 \times \mathbf{X} 4$ & -0.019263 & 0.001589 & -12.123 & 0.000 \\
\hline
\end{tabular}

Table 7. ANOVA for Surface Roughness using RSM

\begin{tabular}{|c|c|c|c|c|c|}
\hline Source & DF & SS & MS & F-value & P \\
\hline Regression & 14 & 1.45082 & 0.103630 & 0.103630 & 0.00 \\
\hline Linear & 4 & 0.53823 & 0.101113 & 0.101113 & \\
\hline Square & 4 & 0.50600 & 0.096197 & 0.096197 & \\
\hline Interaction & 6 & 0.40659 & 0.067765 & 0.067765 & \\
\hline
\end{tabular}




\begin{tabular}{|c|c|c|c|c|c|}
\hline $\begin{array}{c}\text { Residual } \\
\text { Error }\end{array}$ & 16 & 0.00782 & 0.000489 & 0.000489 & \\
\hline $\begin{array}{c}\text { Lack-of- } \\
\text { Fit }\end{array}$ & 9 & 0.00647 & 0.000719 & 0.000719 & 0.04 \\
\hline Pure Error & 7 & 0.00135 & 0.000192 & 0.000192 & \\
\hline Total & 30 & 1.45864 & & & \\
\hline
\end{tabular}

The adequacy of the model was checked by analysis of variance (ANOVA). Table.7 of ANOVA for Ra shows that the p-value for model is less than 0.05 , which indicates that the model is significant. In quadratic term speed, feed, Interference and no. of pass have significant effect. The model has significant interactions of interference and spindle speed, interference and no. of pass. Table 3 shows that the p-value for interaction term is less than 0.05 for $\mathrm{Ra}$, this means that the effect of interference on Ra depends on the spindle speed. Non-significant lack-of-fit is required for any model to be fitted.

\subsection{Comparison of MLR and RSM model}

Fig. 3 and Fig.4 represent the residual plots for MLR and RSM model respectively. It shows RSM technique is more feasible in predicting the surface roughness than the MLR technique.

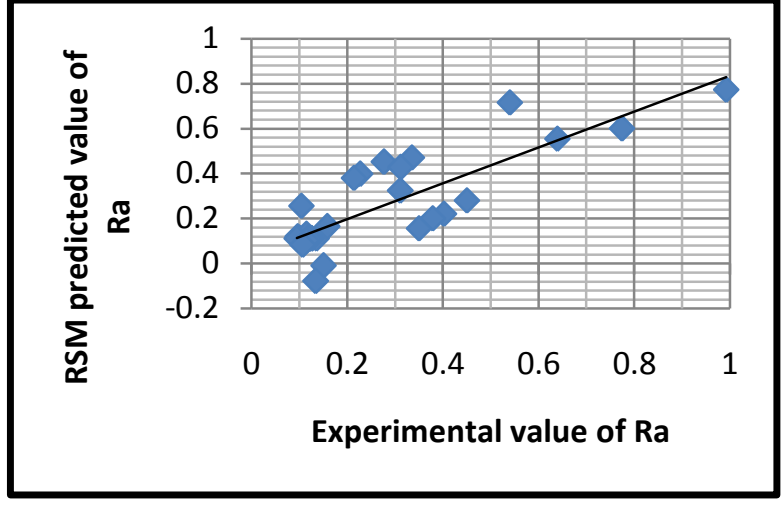

Fig 4: Regression plot for Ra using RSM

This might be due to the large amount of data required for developing a sustainable regression model, while the response surface could recognize the relationships with less data for distributed and parallel computing natures. A second reason is the effect of the predictors on the dependent variable, which may not be linear in nature. In other words, the RSM model could probably predict surface roughness with a better performance owing to their greater flexibility and capability to model nonlinear relationships.

Therefore, in the case of data sets with a limited number of observations in which regression models fail to capture reliably, advanced soft computing approaches like RSM may be preferred.

Table 8. Experimental Results Table

\begin{tabular}{|c|c|c|c|c|c|c|c|c|c|}
\hline $\begin{array}{l}\text { Sr. } \\
\text { No }\end{array}$ & $\begin{array}{c}\text { Spindle } \\
\text { Speed } \\
(\text { RPM) }\end{array}$ & $\begin{array}{c}\text { Interference } \\
\quad(\mathbf{m m})\end{array}$ & $\underset{(\mathbf{m m} / \mathbf{r e v})}{\text { Feed }}$ & $\begin{array}{c}\text { No. of } \\
\text { Tool } \\
\text { Passes } \\
\end{array}$ & $\begin{array}{l}\text { Exp. value } \\
\text { of Ra }\end{array}$ & $\begin{array}{c}\text { MLR } \\
\text { Prediction }\end{array}$ & $\begin{array}{c}\text { RSM } \\
\text { Prediction }\end{array}$ & $\begin{array}{l}\text { Error } \\
\text { MLR }\end{array}$ & $\begin{array}{c}\text { Error } \\
\text { RSM }\end{array}$ \\
\hline 1 & 0 & 0 & 0 & 0 & 0.122 & 0.267 & 0.110 & -0.145 & 0.011 \\
\hline 2 & 2 & -2 & -2 & 2 & 0.277 & 0.295 & 0.451 & -0.018 & -0.174 \\
\hline 3 & -2 & -2 & -2 & -2 & 0.402 & 0.408 & 0.220 & -0.006 & 0.181 \\
\hline 4 & 2 & 2 & 2 & 2 & 0.15 & 0.126 & -0.009 & 0.023 & 0.159 \\
\hline 5 & 2 & 2 & -2 & -2 & 0.104 & 0.123 & 0.255 & -0.0192 & -0.151 \\
\hline 6 & -2 & -2 & 2 & -2 & 0.774 & 0.522 & 0.599 & 0.251 & 0.174 \\
\hline 7 & 0 & 0 & 0 & 0 & 0.126 & 0.267 & 0.110 & -0.141 & 0.015 \\
\hline 8 & 0 & 0 & 0 & 2 & 0.1 & 0.211 & 0.112 & -0.111 & -0.012 \\
\hline 9 & -2 & -2 & 2 & -1 & 0.639 & 0.494 & 0.554 & 0.144 & 0.084 \\
\hline 10 & 0 & 0 & 0 & 0 & 0.136 & 0.267 & 0.110 & -0.131 & 0.025 \\
\hline 11 & -2 & 2 & 2 & 2 & 0.134 & 0.126 & -0.077 & 0.007 & 0.211 \\
\hline 12 & -1 & 0 & 0 & 0 & 0.096 & 0.267 & 0.120 & -0.171 & -0.024 \\
\hline 13 & 2 & -2 & 2 & -2 & 0.992 & 0.522 & 0.772 & 0.469 & 0.219 \\
\hline 14 & 0 & 0 & 0 & 0 & 0.099 & 0.267 & 0.110 & -0.168 & -0.011 \\
\hline 15 & 0 & 0 & 0 & 0 & 0.125 & 0.267 & 0.110 & -0.142 & 0.014 \\
\hline 16 & 2 & 2 & 2 & -2 & 0.227 & 0.237 & 0.398 & -0.010 & -0.171 \\
\hline 17 & 2 & -2 & -2 & -2 & 0.379 & 0.407 & 0.200 & -0.028 & 0.178 \\
\hline 18 & 1 & 0 & 0 & 0 & 0.115 & 0.266 & 0.132 & -0.151 & -0.017 \\
\hline 19 & -2 & -2 & -2 & 2 & 0.335 & 0.296 & 0.471 & 0.038 & -0.136 \\
\hline 20 & 2 & 2 & -2 & 2 & 0.35 & 0.011 & 0.156 & 0.338 & 0.193 \\
\hline 21 & 0 & 0 & 0 & 0 & 0.117 & 0.267 & 0.110 & -0.150 & 0.006 \\
\hline 22 & -2 & 2 & -2 & -2 & 0.214 & 0.123 & 0.380 & 0.090 & -0.166 \\
\hline 23 & 0 & -2 & 0 & 1 & 0.312 & 0.381 & 0.427 & -0.069 & -0.115 \\
\hline 24 & 2 & -2 & 2 & 2 & 0.54 & 0.410 & 0.715 & 0.129 & -0.175 \\
\hline 25 & 0 & 0 & 0 & 0 & 0.095 & 0.267 & 0.110 & -0.172 & -0.015 \\
\hline 26 & 0 & 0 & 0 & 0 & 0.12 & 0.267 & 0.110 & -0.147 & 0.009 \\
\hline 27 & 0 & 0 & 0 & 1 & 0.115 & 0.239 & 0.101 & -0.124 & 0.013 \\
\hline 28 & 0 & 2 & -2 & 0 & 0.158 & 0.067 & 0.164 & 0.090 & -0.006 \\
\hline 29 & -2 & 0 & 2 & -2 & 0.311 & 0.380 & 0.323 & -0.069 & -0.012 \\
\hline 30 & 0 & 2 & 1 & 0 & 0.107 & 0.153 & 0.083 & -0.046 & 0.023 \\
\hline 31 & -2 & 2 & -2 & 2 & 0.45 & 0.012 & 0.280 & 0.437 & 0.169 \\
\hline
\end{tabular}




\section{CONCLUSION}

With the help of a generated prediction model of surface roughness optimum set of parameters can be found out for better surface roughness.

It is found that the model is significant and adequate to represent the relationship between the variables and response.

The present investigation aimed at the comparison of RSM and MLR model for Surface roughness prediction. The comparative study of RSM model and the MLR model for Surface roughness prediction draws the following conclusions.

The results obtained during preliminary test suggest that the RSM approach is a promising tool for accurately estimating Surface roughness compare to MLR model.

The result shows that the RSM technique is far better than MLR method.

\section{REFERENCES}

[1] Sastry, M. N. P., Devi, K. D., \& Reddy, K. M. (2012). Analysis and optimization of machining process parameters using design of experiments. Industrial Engineering Letters, 2 (9), 23-32.

[2] Skalski, K., Morawski, A., \& Przybylski, W. 1995. Analysis of contact elastic-plastic strains during the process of burnishing. International journal of mechanical sciences, 37 (5), 461-472.
[3] El-Axir, M. H., Othman, O. M., \& Abodiena, A. M. 2008. A study on the inner surface finishing of aluminum alloy 2014 by ball burnishing process. Journal of materials processing technology, 202 (1), 435-442.

[4] El-Axir, M. H., Othman, O. M., \& Abodiena, A. M. 2008. Improvements in out-of-roundness and microhardness of inner surfaces by internal ball burnishing process. Journal of materials processing technology, 196 (1), 120-128.

[5] Sagbas, A., Kahraman, F. 2009. Determination of optimal ball burnishing parameters for surface hardness. Materiali in tehnologije, 43 (5), 271-274.

[6] Sagbas, A. 2011. Analysis and optimization of surface roughness in the ball burnishing process using response surface methodology and desirability function. Advances in Engineering Software, 42 (11), 992-998.

[7] Travieso-Rodríguez, J. A., Dessein, G., \& GonzálezRojas, H. A. 2011. Improving the surface finish of concave and convex surfaces using a ball burnishing process. Materials and Manufacturing Processes, 26 (12), 1494-1502.

[8] Grzesik, W., \& Żak, K. 2012. Modification of surface finish produced by hard turning using superfinishing and burnishing operations. Journal of Materials Processing Technology, 212 (1), 315-322. 